\title{
Blood pressure and the kidney
}

\author{
JD SWALES
}

From the Department of Medicine, University of Leicester, Leicester

The association between the kidney and the circulation has been known from ancient times. Chinese literature of the second century $\mathrm{BC}$ for instance contains a clear recognition of the relationship between hardening of the pulse and renal disease. Understanding was however severely limited by the poor technology available up to comparatively recent times. Thus Bright ${ }^{1}$ correctly deduced that left ventricular hypertrophy in renal disease reflected raised systemic arterial pressure. He incorrectly concluded that the hypertension was due to the increased resistance offered by the diseased renal vasculature. The assumption that clinical hypertension was invariably caused by renal disease persisted until Allbutt ${ }^{2}$ distinguished between essential and renal hypertension in 1896. The extent of the role of the kidney in hypertension has been the subject of debate ever since.

\section{Renal mechanisms}

The twentieth century has provided powerful tools for the analysis of the role of the kidney in hypertension. Experimental studies initiated by Goldblatt's group $^{3}$ have provided reproducible animal models of hypertension. These have found a clinical counterpart in the development of dialysis therapy which allows anephric patients to be maintained in a good state of health and also permits more carefully controlled studies of the effect of changes in fluid and electrolyte balance on blood pressure. These advances in human and animal procedures were paralleled by equally exciting laboratory developments beginning with the techniques for electrolyte analysis, and followed by the application of biochemistry and physiology to the kidney and its function. More recently knowledge of the reninangiotensin system has enabled chemists to synthesise inhibitors and antagonists to specific components of that system. Mostly these techniques have been devoted to elucidating the properties of the two renal systems which are known to be important in blood pressure maintenance-namely, the control of salt and water balance and the renin-angiotensin system.
SODIUM-DEPENDENT HYPERTENSION

The best example of hypertension produced by sodium and water retention is the raising of blood pressure observed in anephric patients and many patients with terminal renal disease. ${ }^{4-6}$ Under these circumstances the blood pressure level is correlated with expansion of the extracellular fluid and can be controlled by dialysis with removal of sodium and water. While this is the classic pattern, there have always been wide discrepancies in the reported incidence of dialysis-sensitive and dialysis-resistant hypertension from different units. This may be partly due to the degrees of enthusiasm with which salt depletion is carried out by dietary supervision and dialysis. In addition it seems likely that renal atrophy proceeding during chronic dialysis reduces the role of the other renal mechanisms with the passage of time.

The mechanism by which sodium causes the blood pressure to rise in the presence of reduced renal mass is still the subject of keen debate. The most widely promulgated explanation is provided by the autoregulatory hypothesis of Guyton and coworkers. This group studied the sequence of events which occurs when partially nephrectomised dogs are loaded with salt. ${ }^{7}$ The Guyton hypothesis ${ }^{8}$ postulates that volume expansion leads to an increase in venous return to the heart and a consequent rise in cardiac output. This results in over-perfusion of tissue beds, and protective autoregulatory vasoconstriction which reduces peripheral flow back to normal levels at the expense of increased blood pressure.

While autoregulation can be demonstrated in isolated vessels and in some tissue beds, "whole body autoregulation" is a much more nebulous concept since as often as not this response is over-ridden by one of the multitude of other factors that controls the calibre of resistance vessels. ${ }^{9}$ However, there is more direct evidence against the Guyton hypothesis from haemodynamic studies of patients on haemodialysis. ${ }^{10}$ In such patients the rise in blood pressure produced by saline administration is more frequently associated with an initial rise in peripheral resistance, only a minority of patients showing the Guytonian 
sequence of an initial rise in cardiac output followed by a rise in peripheral resistance. These results are consistent with studies in rabbits with renal wrap hypertension (the production of hypertension experimentally by enclosing one or both kidneys in cellophane-Eds) which is also usually associated with an initial rise in peripheral resistance. ${ }^{11}$ While the postoperative rise in cardiac output was sometimes observed this could also be demonstrated in control animals which did not develop hypertension. Another group ${ }^{12}$ has shown that changes in cardiac output could be produced in dogs by changes in sodium balance during the development of renovascular hypertension, quite independently of blood pressure. It is difficult to escape the conclusion from studies such as these that the rise in cardiac output is not a sine qua non for blood pressure elevation: even where it occurs it is a non-specific consequence of the surgical procedure.

Inevitably therefore interest has been focused upon the effect of sodium upon the peripheral blood vessels. Three hypotheses have been put forward (Table). The suggestion that sodium and fluid

\section{Hypotheses put forward to explain effect of sodium ion on peripheral resistance}

\footnotetext{
1 Arteriolar wall sodium retention causing increased wall :lumen ratio (Tobian).

2 Increased smooth muscle membrane ionic turnover enhancing reactivity (Jones).

3 Increased intracellular sodium content of smooth muscle enhancing contractility (Blaustein).
}

retention in the arteriolar wall increases resistance to flow is the oldest and is supported by the demonstration of increased arterial sodium in several forms of experimental hypertension. ${ }^{13}$ Whether such sodium lies in the extracellular fluid compartment or within the cells is unknown although claims have been made for both sites. ${ }^{1314}$ The problem in assessing the studies of arterial wall sodium is one of differentiating cause and effect. Increased perfusion pressure causes an increase in arterial and arteriolar wall diameter, expansion of the extracellular space and enhanced non-osmotic binding of sodium. ${ }^{15}$ In addition, malignant hypertension gives rise to plasma insudation into the arterial wall which must substantially affect its electrolyte composition. The possibility that increased arterial wall sodium is a consequence rather than a cause of hypertension is supported by the observation that in dogs with experimental coarctation of the aorta increased sodium content is only demonstrable in that part of the aorta exposed to high pressure. ${ }^{16}$

Recently great interest has been aroused by the suggestion that the sodium ion may exert an effect either by changes in membrane conduction or smooth muscle contraction. Thus, the aortic smootho muscle membrane in spontaneously hypertensive rats shows enhanced ionic turnover, and it has beenc? postulated that the consequent depolarisation enhances smooth muscle responsiveness to vaso- $\frac{\overline{0}}{\bar{n}}$ constrictor stimuli. ${ }^{17}$ Other groups have suggested $\overline{\frac{s}{f}}$ that the abnormality occurs further down the chain of events at the level of smooth muscle contraction. According to this hypothesis there is a linkagebetween alterations in intracellular sodium and ${ }_{-}^{\circ}$ calcium ions, modifying smooth muscle contractility. $\vec{\omega}$ Such hypotheses provide a potential solution tog several observed phenomena which cannot beo explained simply in terms of expansion of extra- $\omega$ cellular fluid volume. Thus abnormalities in mem brane sodium transport have been demonstrated in.the red cells ${ }^{19-21}$ and the white cells ${ }^{22}$ of patients with $\vec{\sim}$ essential hypertension. Even where extracellularw fluid volume appears to be expanded, sodium may be으 having an additional effect. Thus, hypertensioninduced by mineralocorticoids appears to be related $Z$ to the handling of sodium by peripheral blood vessels rather than to expansion of the extracellular fluid. ${ }^{23} 3$ Mineralocorticoid hypertension can be induced inథ sheep which have been bilaterally nephrectomised. so that renal retention of sodium does not seem to fec an essential prerequisite. ${ }^{24}$ The development hypertension in patients with primary aldosteronis is associated with a rise in peripheral resistance rather than cardiac output ${ }^{25}$ and the administrationo of mineralocorticoid hormones experimentally leads to enhanced responsiveness to vasoconstrictor $\stackrel{\mathbb{Q}}{\varrho}$ stimuli. ${ }^{26} 27$

Pre-eclamptic toxaemia of pregnancy may be related to sodium retention in some equally complex $\supsetneq$ way. Thus, this condition is associated with reducedo plasma activities of renin, and concentrations of angiotensin II and aldosterone in comparison with? normal pregnancy, ${ }^{28}$ and pre-eclamptic women show 3 a reduced capacity to excrete sodium loads. ${ }^{29}$ It is possible therefore that the sodium ion accounts for the well documented hypersensitivity to angiotensin II which can be seen at a relatively early stage in the ? pregnancies of women who are later to develop full $)$ manifestations of pre-eclamptic toxaemia. ${ }^{30}$

There is however a missing link between the sodium ion and the peripheral blood vessel. How does sodium loading in, for instance, bilaterally nephrectomised subjects cause peripheral vascular $\omega$ constriction? Clearly changes in serum sodium concentration are not responsible since quite $a \stackrel{c}{c}$ marked rise or fall in serum sodium can occur with- $\Phi$ out any corresponding change in blood pressure. If ${ }^{?}$ sodium loading does indeed have an effect on vascular $\frac{T}{-}$ smooth muscle one possibility is that there are $\frac{\mathrm{O}}{\mathrm{D}}$ 
changes in circulating substances which influence membrane sodium transport in some way. This cause has been espoused by de Wardener and McGregor" who have postulated that "natriuretic hormone" concentrations raised by sodium loading influence cellular membrane sodium handling with a consequent rise in intracellular sodium and enhanced contractility through changes in the intracellular concentration of calcium ions. While this hypothesis would explain some of the changes which have been observed in membrane sodium transport in clinical and experimental forms of hypertension, it would seem difficult to explain the insensitivity of blood pressure to a wide range of changes in sodium intake which would presumably alter substantially circulating concentrations of "natriuretic hormone": neither does this hypothesis explain changes in vascular reactivity which can be demonstrated with artificial perfusion media unless it is argued that the effect of natriuretic hormone upon sodium pump activity is irreversible. Such irreversibility would seem to remove much of the possibility for flexibility which is such an important feature of blood pressure control.

In summary therefore it is likely that the sodium ion is an important factor in some clinical and experimental forms of hypertension through an effect upon peripheral vascular smooth muscle. If so, fluid volume expansion would appear to be only indirectly associated with the rise in blood pressure.

\section{RENIN-DEPENDENT HYPERTENSION}

Renal hypersecretion of renin is one of the mechanisms by which the kidney preserves blood pressure in the face of reduced renal perfusion pressure, fluid depletion or blood loss. Since the renin-angiotensin system is extremely effective in raising blood pressure through the production of the pressor octapeptide angiotensin II, this system could, theoretically, cause clinical hypertension. There is little doubt that this is the case in certain unusual forms of hypertension. The most clear-cut of these syndromes are those in which there is a renin-secreting tumour-for example, in hemangiopericytoma of the kidney, ${ }^{32}$ and Wilms' tumour. ${ }^{33}$ The renin-angiotensin system is probably also responsible for high blood pressure in a minority of patients under treatment with intermittent haemodialysis for terminal renal disease whose blood pressure does not respond to the removal of sodium until bilateral nephrectomy has been carried out. Usually these patients have very high renin and angiotensin II levels 5 and their blood pressure shows a major fall in response to infusion of the angiotensin II blocking agent saralasin. ${ }^{34}$ Hypertension is also corrected by renin-angiotensin blockade in some patients with Cushing's syndrome and it seems possible that the renin-angiotensin system may play a role in this condition too. ${ }^{35}$ The role of the reninangiotensin system in more common forms of hypertension is much more debatable. In the commonest form of hypertension of all-that is, essential hypertension, there is no convincing evidence that the renin-angiotensin system plays any role at all. ${ }^{36}$

\section{RENOVASCULAR HYPERTENSION}

There is now an enormous literature upon the role of the renin-angiotensin system in hypertension produced by renal ischaemia. One of the fundamental difficulties about clinical studies of such renovascular hypertension is that atheromatous renal artery stenosis is frequently found at necropsy in patients who are normotensive, and is also extremely common in patients who otherwise have a typical clinical picture of essential hypertension. ${ }^{37}$ The difficulty therefore is in discriminating cause and effect. Studies of renin secretion in patients with renal artery stenosis are of uncertain relevance unless the subsequent clinical course of such patients indicates that hypertension responded to surgical correction of renal ischaemia. Such surgically correctable renovascular hypertension is associated with raised plasma renin activities in the majority of cases, ${ }^{38-40}$ but in a minority of patients, plasma renin lies within the normal range. Thus there are well documented cases in which there was a favourable response to surgery despite a normal plasma renin activity. ${ }^{41-43}$ However, more direct evidence on the relevance of renin hypersecretion to renovascular hypertension can be obtained by following the postoperative blood pressure and plasma renin in patients who have had unilateral nephrectomy or a revascularisation procedure for renovascular hypertension. ${ }^{44} \mathrm{We}$ have studied eight patients all of whom initially had a substantially raised plasma renin activity. Plasma renin fell significantly in all becoming normal in six and borderline in the remaining two patients (Fig. 1). Blood pressure only fell to normal levels in three patients. Three of the patients showed a partial reduction in blood pressure and in the remaining two, blood pressure was unchanged. Of the six patients with a normal plasma renin, three remained hypertensive in the postoperative period. There is thus a clear-cut divergence between postoperative changes in plasma renin activity and postoperative biood pressure (Fig 2). This fact has important implications for the use of measurements of renin in blood from the renal veins to predict the outcome of surgery. ${ }^{39}$ The most commonly used criterion of surgical correctability is an increase in renal vein renin activity on the ischaemic side. The ratio 

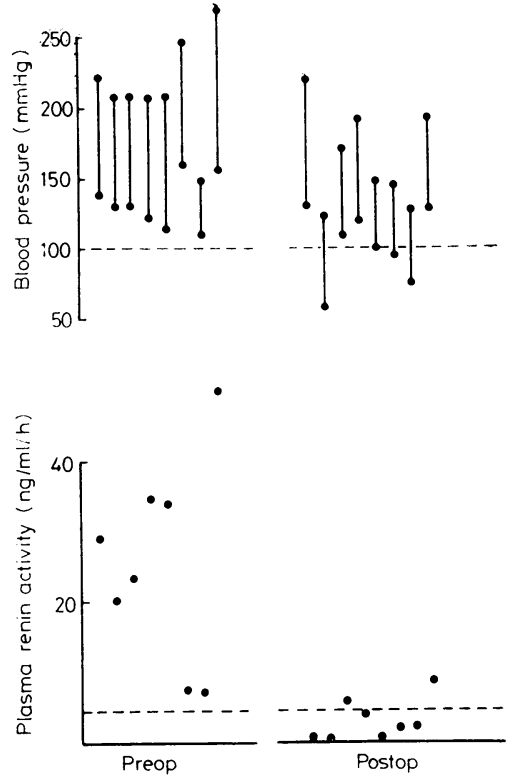

Fig. 1 Preoperative and postoperative blood pressure and plasma renin activity in eight patients who underwent either unilateral nephrectomy or a revascularisation procedure for renovascular hypertension. Although high plasma renin activity was corrected in every case, blood pressure remained raised in some patients. All plasma renin activity values reported are in patients not receiving antihypertensive medication. Postoperative blood pressure values are taken from outpatient records 1 month to $4 \mathrm{yr}$ after surgery before treatment was restarted in patients who required medication.

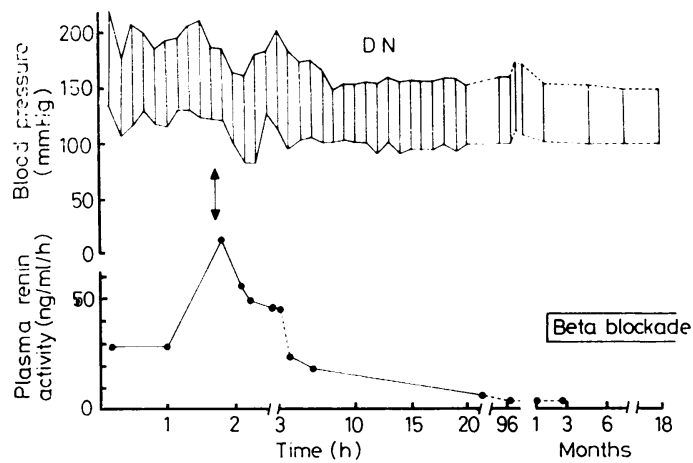

Fig. 2 Blood pressure and plasma renin activity of a patient who underwent surgical correction of renal artery stenosis produced by an atheromatous plaque. Plasma renin activity was restored to normal, but blood pressure was only partially corrected and required treatment with a beta-blocker. The arrow indicates the time of operation. (From Swales JD. Clinical Hypertension. Chapman and Hall, 1979.) advocated as the cut-off point varies between 1.4 and 2.455 although in one large series the $95 \%$ confidence limit was a ratio of $2: 1 .^{46}$ Other groups have emphasised, in addition, the importance of showing that renin secretion is suppressed on the non-ischaemic side-that is, renin activity in arterial blood reaching the kidney is equal to that in the venous effluent from the kidney. ${ }^{39}$ While such tests have been enthusiastically recommended by some centres there are grave theoretical and practical objections to their uncritical usage. Theoretically the main objection lies in the substantial clinical and experimental evidence that the renin-angiotensin system is not solely responsible for maintaining the blood pressure in renovascular hypertension. The demonstration of renin hypersecretion by the ischaemic kidney may therefore simply be acting as a marker of renal ischaemia. In practice discrepant results have been reported from different centres. This is not entirely surprising as some groups follow a policy of only operating on patients who show clear-cut lateralisation of renal vein renin measurements. Under these circumstances it is impossible to assess the incidence of false-negatives-that is, the incidence of patients whose blood pressure responds to surgery despite negative renal vein renin measurements. The incidence of such false negative ratios may be very high indeed. 454748

An alternative strategy employs the angiotensi antagonist sarcosine-1-alanine-8-angiotensin $\mathbf{k}$. (saralasin). It is argued that the blood pressure response to saralasin indicates whether hypertension is "angiotensinogenic" or not. 49 "Angiotensinogenic hypertension" is not of course identical with renovascular hypertension. In addition to the evidence that renovascular hypertension is not wholly attributable to renin hypersecretion, there is also the undoubted fact that high plasma renin activities are found in other forms of hypertension-for example, malignant hypertension and high-renin essential hypertension. ${ }^{50}$ Patients with these conditions will of course also show a fall in blood pressure when infused with saralasin.

In general there is a close relationship between plasma renin activity and the fall in blood pressure induced by saralasin. Despite this, some patients have been described who show a depressor response to saralasin and a favourable response to surgery $N$ despite normal plasma renin activities and no evidence of lateralisation on renal vein renin $\widetilde{N}$ measurements. ${ }^{51}$ However, patients have also been $\underset{\omega}{ }$ described in whom the high blood pressure responded to surgical treatment despite the absence of a fall in 6 blood pressure in response to saralasin. ${ }^{41}$ In general $\mathbb{D}$ saralasin infusion would seem to have no substantial $\stackrel{\mathcal{\infty}}{\rightarrow}$ advantage over traditional methods for assessing $\underset{T}{T}$ surgical correctability. Further, the absence of a fall 
in blood pressure when saralasin is infused into hypertensive patients with a normal plasma renin activity suggests that the renin-angiotensin system is not of major importance in maintaining the high blood pressure in those patients with renovascular hypertension who have normal or only slightly raised plasma renin activities.

EXPERIMENTAL RENOVASCULAR

HYPERTENSION

Inevitably, clinical hypertension is a poor model for investigating the pathogenesis of renal hypertension since the onset of hypertension can rarely be observed. Treatment alters many of the variables which are relevant to blood pressure control and surgical correction of hypertension is attended by many confounding variables. Some of these disadvantages can be overcome by the study of experimental renovascular hypertension.

The most commonly used experimental model for renovascular hypertension is based upon Goldblatt's original dog studies. ${ }^{3}$ A constricting clip or clamp is placed upon the renal artery. The opposite kidney may be removed (Goldblatt 1-kidney 1-clip hypertension) or left in situ (Goldblatt 2-kidney 1-clip hypertension). Hypertension is easier to produce and more severe in the one kidney model. Since hypertension is more difficult to induce in the rabbit and the dog than in the rat, most studies of the first two species have been carried out with the 1-kidney model. There are however disadvantages. Reduction in perfusion pressure to a single kidney produces sodium retention. Whilst this may contribute to some of the manifestations of hypertension in the 1kidney model it is not essential. ${ }^{11}{ }^{52}$ Sodium retention may however complicate the interpretation of physiological studies. With the 2-kidney model the presence of a normal kidney prevents significant sodium retention. Indeed increased perfusion pressure to the normal kidney occurring during the development of hypertension produces a natriuresis so that Goldblatt 2-kidney 1-clip, hypertension is associated with a slightly negative sodium balance. ${ }^{53}$ Conversely, during reversal of this form of hypertension by removal of the renal artery clip sodium is retained and the negative balance is corrected. ${ }^{54}$

Changes in plasma renin activity are more complex. Immediately after renal artery constriction there is a shortlived rise in activity which probably accounts for immediate postoperative hypertension. ${ }^{55}$ After this, blood pressure temporarily returns to normal and then gradually rises over a period of days or weeks depending upon the species and the degree of constriction of the renal artery. This phase of hypertension is associated with an increase in plasma renin activity in most species studied although the rise is less conspicuous in the rabbit and the dog. ${ }^{36}$ As hypertension enters the chronic phase, the activity tends to fall although it may remain slightly raised in the rat. ${ }^{54}$ The blood pressure response to renin-angiotensin blockade with saralasin tends to follow the plasma renin activity. Thus infusion of this agent produces a fall in blood pressure in rats with two kidney hypertension of a few weeks duration, ${ }^{56} 57$ whilst after three to four months no blood pressure response occurs. ${ }^{5658}$ An earlier observation that prolonged infusion of saralasin produced a slow fall in blood pressure over $12 \mathrm{~h}^{59}$ has not been confirmed in long-standing Goldblatt 2-kidney hypertension. ${ }^{60}$ The converting enzyme inhibitor captopril produces a greater fall in blood pressure at all stages of hypertension. ${ }^{54} 61$ While the better response to captopril might indicate that saralasin underestimates the role of the renin-angiotensin system in hypertension (perhaps through intrinsic agonist activity), it is also possible that captopril lowers blood pressure by a mechanism additional to reninangiotensin blockade. ${ }^{62}$

In view of these uncertainties about the specificity of renin/angiotensin inhibitors we have studied the effect of surgical reversal of renovascular hypertension during renin-angiotensin blockade with saralasin or captopril. ${ }^{63}$ In these experiments the inhibitor was infused into rats with Goldblatt 2kidney 1-clip hypertension for $15 \mathrm{~h}$, and the constricting clip or the ischaemic kidney was then removed, while maintaining the inhibitor infusion. Blockade made no difference to the slow fall in blood pressure which occurred in the first few postoperative hours and which completely corrected hypertension in most instances.

There is therefore evidence against the view that the renin-angiotensin system maintains the high blood pressure in renovascular hypertension (2kidney 1 clip model). One explanation of the fact that plasma renin activity may be normal in renovascular hypertension is the possibility that it does not reflect the degree of activity of the reninangiotensin system in blood pressure maintenance. It has been argued for instance that local renin activity within the resistance vessel wall may maintain blood pressure through the local generation of angiotensin II. Whilst direct and indirect evidence suggests that such local generation of angiotensin II does occur, we have been unable to show that there is a divergence between vascular and plasma renin activities except for a short period after bilateral nephrectomy. ${ }^{64}$ In addition, the close relation between the fall in blood pressure produced by saralasin and the plasma renin activity in a wide variety of situations suggests that plasma renin does in fact reflect accurately the role of the renin-angiotensin system in 
blood pressure maintenance. An alternative hypothesis is that the circulation is unduly sensitive to renin. ${ }^{65}$ Thus blood pressure levels observed in renovascular hypertension were higher than those produced by similar plasma angiotensin II concentrations induced in normal subjects by infusion. The difficulty with such a hypothesis is that vascular reactivity to angiotensin II is altered when blood vessels hypertrophy. Thus hyperresponsiveness can be a consequence of hypertension and not a cause of it. ${ }^{66}$ Furthermore, changes in plasma renin activity may affect responsiveness to exogenous angiotensin II by changing the degree of occupancy of vascular angiotensin receptors by endogenous angiotensin. ${ }^{67}$ There is at present no convincing evidence for specific hyperresponsiveness to angiotensin II as a mechanism for maintaining blood pressure in renovascular hypertension.

Another possibility is that the structural changes which can be demonstrated in the arterioles become progressively more important with the passage of time, and replace renin hypersecretion as a factor in maintaining blood pressure. ${ }^{66}$ Against this view is the fact that, according to some groups, removal of the constricting clip restores blood pressure to normal at any stage in the Goldblatt 2-kidney 1-clip model.54 68 Floyer observed persisting hypertension in about half the animals when the constricting clip was removed although blood pressure was substantially reduced in all the rats. ${ }^{69}$ The success of surgery both in man and the rat together with the fact that the fall in blood pressure occurs within a few hours of removal of the constricting clip ${ }^{63}$ argues against reversal of structural changes as the mechanism of improvement.

\section{A RENAL VASODEPRESSOR SYSTEM?}

The conundrum remains therefore; how is blood pressure maintained in renovascular hypertension if neither sodium retention nor renin hypersecretion can be the sole factor? It seems likely that another renal system is involved. Muirhead ${ }^{70}$ has presented a strong case for a medullary antihypertensive function. In summary his evidence is based upon several experiments. Firstly, he and other groups were able to demonstrate that experimental sodium-volume overload hypertension was prevented by a renal transplant independently of sodium excretion. Secondly, ureterocaval anastomosis prevented this form of hypertension although the excretory function of the kidney was of course abolished. Ureteral ligation which destroys renal medullary function failed to have this protective effect however. Medullary transplants were found to prevent or reverse Goldblatt 1-kidney hypertension. More recently, Muirhead has succeeded in isolating antihypertensive lipids from medullary interstitial cell tissue culture. Whether these studies can be applied to clinical and experimental situations where such volume expansion does not occur is still o़ uncertain but it is clear from the vast experimental $\bar{O}$ literature on renovascular hypertension that we must try to demonstrate and characterise other $\frac{\bar{\omega}}{\partial}$ blood pressure control systems apart from sodium balance and the renin-angiotensin system.

\section{References}

${ }^{1}$ Bright R. Tabular view of the morbid appearances in 100 cases connected with albuminous urine with observations. Guy's Hospital Reports 1836;1:380-400.

2 Allbutt C. Senile plethora, or high arterial pressure in elderly persons. Abstr Trans Hunterian Society 77th Session 1896:38-57.

${ }^{3}$ Goldblatt H, Lynch J, Hanzal RF, Summerville WW. Studies on experimental hypertension: 1 . The production $\vec{N}$ of persistent elevation of systolic blood pressure by $\underset{\omega}{\omega}$ means of renal ischaemia. $J$ Exp Med 1934;59:347-79.

4 Vertes V, Cangiano JL, Berman LB, Gould A. Hypertension in end-stage renal disease. $N$ Engl J Med 1969; 280:978-81.

${ }^{5}$ Weidmann P, Maxwell $\mathrm{MH}$. The renin angiotensin aldosterone system in terminal renal failure. Kidney Int $1975 ; 8$, suppl 5:219-34.

- Wilkinson R, Scott DF, Uldall PR, Kerr DNS. Plasma Ф renin and exchangeable sodium in the hypertension of $\vec{\odot}$ chronic renal failure. $Q J$ Med 1970;39:377-94.

7 Guyton AC, Coleman TG, Bower JD, Granger H. Circulatory control in hypertension. Circ Res 1970;26 suppl II :135-47.

${ }^{8}$ Guyton AC, Coleman TG, Cowley AW, Sheel KW Manning RD, Norman RA. Arterial pressure regulation. $\bar{\partial}$ In: Laragh $\mathbf{J H}$, ed. Hypertension manual. New York: Yorke Medical, 1974:111-34.

9 Folkow B, Neil E. Circulation. London: Oxford University Press, 1971.

${ }^{10}$ Kim KE, Onesti G, Del Guercio ET, Greco J, Fernandes $M$, Swartz C. The haemodynamic response to salt and water loading in patients with end-stage renal disease and anephric man. Clin Sci Mol Med 1976; 51, suppl 3: 2235-55.

${ }^{11}$ Fletcher PJ, Korner PI, Angus JA, Oliver JR. Changes in cardiac output and total peripheral resistance during $\bar{O}$ development of renal hypertension in the rabbit. Circ 3 Res 1976;39:633-9.

12 Davis JO, Stephens GA, Freeman RH, De Forrest JM. 윽 Changes in cardiac output during the development of renal hypertension in sodium depleted dogs. Clin Sci 윽

Mol Med 1978 ;suppl 4:221-3.
13 Tobian L. How sodium and the kidney relate to the hypertensive arteriole. Fed Proc 1974;33:138-42.

14 Madden JA, Smith GA, Llaurado JG. Sodium distribution N in mesenteric arterial wall of rats with hypertension induced by drinking saline. Clin Sci 1979;56:471-8.

15 Jansson $O$, Lundgren $Y$, Wennergren $G$. The distribution of sodium in aortic walls from spontaneously hyper- $\omega$ tensive and normotensive rats. Acta Physiol Scand 1975 ; 93:548-52.

16 Hollander W, Kramsch DM, Farmelant M, Madoff IM. Arterial wall metabolism in experimental coarctation of the aorta of short duration. J Clin Invest $1968 ; 47: 1221-9 .{ }^{-}$

17 Jones AW. Altered ion transport in vascular smooth muscle from spontaneously hypertensive rats: influence 
of aldosterone, norepinephrine and angiotensin. Circ Res 1973;33:563-72.

${ }^{18}$ Blaustein MP. Sodium ions, calcium ions, blood pressure regulation and hypertension: a reassessment and a hypothesis. Am J Physiol 1977;232:165-73.

19 Postnov Y, Orlov S, Shevchenko A, Adler A. Altered sodium permeability, calcium binding and $\mathrm{Na}^{+}, \mathrm{K}^{+}$ATPase activity in the red blood cell membrane in essential hypertension. Pfluegers Arch 1977;371:263-9.

${ }^{20}$ Garay RP, Elghozi JL, Dagher G, Meyer P. Laboratory distinction between essential and secondary hypertension by measurement of erythrocyte cation fluxes. $N$ Engl J Med 1980;302:769-71.

${ }^{21}$ Canessa M, Adragna N, Solomon HS, Connolly TM, Tosteson DC. Increased sodium-lithium countertransport in red cells of patients with essential hypertension. $N$ Engl J Med 1980;302:772-6.

${ }^{22}$ Edmondson RPS, Thomas RD, Hilton PJ, Patrick J, Jones NF. Abnormal leucocyte composition and sodium transport in essential hypertension. Lancet $1975 ; \mathrm{i}: 1003-5$.

${ }^{23}$ Bravo EL, Tarazi RC, Duston HP. Multifactorial analysis of chronic hypertension induced by electrolyte-active steroids in trained, unanesthetized dogs. Circ Res 1977; 40, suppl 1: 1140-5.

${ }^{24}$ Fan JSK, Coghlan JP, Denton DA, Scoggins BA, Whitworth JA. Blood pressure and metabolic effects of ACTH in anephric sheep. Clin Exp Pharmacol Physiol 1978;5: 673-7.

${ }^{25}$ Wenting GJ, Man in 'T Veld AJ, Verhoeven RP, Derkx FHM, Schalekamp MADH. Volume-pressure relationships during development of mineralocorticoid hypertension in man. Circ Res 1977;40, suppl 1:1163-70.

${ }^{26}$ Beilin LJ, Wade ND, Honour AJ, Cole TJ. Vascular hyperactivity with sodium loading with desoxycorticosterone-induced hypertension in the rat. Clin Sci 1970;39: 793-810.

27 Berecek KH, Bohr DF. Structural and functional changes in vascular resistance and reactivity in the DOCA hypertensive pig. Circ Res $1977 ; 40$, suppl 1:1146-52.

${ }^{28}$ Weir RJ, Brown JJ, Fraser R, et al. Plasma renin, renin substrate, angiotensin II and aldosterone in hypertensive disease of pregnancy. Lancet 1973; i:291-4.

${ }^{29}$ Chesley LC, Valenti C, Rein H. Excretion of sodium loads by nonpregnant and pregnant normal, hypertensive and pre-eclamptic women. Metabolism 1958;7:575-88.

${ }^{30}$ Gant NF, Worley RJ, Everett RB, MacDonald PC. Control of vascular responsiveness during human pregnancy. Kidney Int 1980;18:253-8.

${ }^{31}$ De Wardener HE, MacGregor GA. Dahl's hypothesis that a saluretic substance may be responsible for a sustained rise in arterial pressure: its possible role in essential hypertension. Kidney Int 1980;18:1-9.

${ }^{32}$ Robertson PW, Klidjian A, Harding LK, Walters G, Lee MR, Robb-Smith AHT. Hypertension due to a reninsecreting tumour. Am J Med 1967;43:963-76.

${ }^{33}$ Ganguly A, Gribble J, Tune B, Kempson RL, Luetscher JA. Renin-secreting Wilms' tumor with severe hypertension. Ann Intern Med 1973;79:835-7.

${ }^{34}$ MacGregor GA, Dawes PM. Angiotensin II blockade in hypertensive dialysis patients. In: Stokes GS, Edwards KDG, eds. Drugs affecting the renin angiotensinaldosterone system. Prog Biochem Pharmacol 1976;12: 190-9.

${ }^{35}$ Dalakos TG, Elias AN, Anderson GH, Streeten DHP, Schroeder ET. Evidence for an angiotensinogenic mechanism of the hypertension of Cushing's syndrome. $J$ Clin Endocrinol Metab 1978;46:114-8.

${ }^{36}$ Swales JD. Renin-angiotensin system in hypertension. Pharmacol Ther 1979;7:173-201.
${ }^{37}$ Heptinstall RH. Pathology of the kidney. 2nd ed. Boston: Little, Brown and Co, 1974:173-4.

${ }^{38}$ Bath NM, Gunnells JC, Robinson PR. Plasma renin activity in renovascular hypertension. Am J Med 1968; 45;381-90.

${ }^{39}$ Vaughan ED. Buhler FR, Laragh JH, Sealey JE, Baer L, Bard RH. Renovascular hypertension: renin measurements to indicate hypersecretion and contralateral suppression, estimate renal plasma flow and score for surgical correctibility. In: Laragh JH, ed. Manual of hypertension. New York: Yorke Medical, 1974:559-82.

${ }^{10}$ Swales JD. The hunt for renal hypertension. Lancet 1976 ;ii : 930-2.

"1 Thomas RD, Ball SG, Lee MR. Failure of saralasin to predict a response to surgery in renovascular hypertension. Lancet 1977; ; :724-6.

${ }^{42}$ Marks LS, Maxwell MH, Kaufman JJ. Non-reninmediated renovascular hypertension. A new syndrome. Lancet 1977 ; i:615-7.

${ }^{13}$ Tucker RM, Strong CG, Brennan LA, Sheps SG, Brown RD, Weinshilboum RM. Renovascular hypertension. Mayo Clin Proc 1978;53:373-7.

14 Maskill M, Bing RF, Thurston H, Bell PRF, Swales JD. Surgical correction of renovascular hypertension. Dissociation between post-operative changes in plasma renin and blood pressure. $Q J$ Med 1980;49:179-90.

45 McDonald JM, Ladenson JH, James T. Renovascular hypertension and plasma renin activity. Clin Chem 1979; 25:289-94.

${ }^{46}$ Maxwell MH, Marks LS, Varady PD, Lupu AN, Kaufman JJ. Renal vein renin in essential hypertension. J Lab Clin Med 1975;86:901-9.

${ }^{17}$ Marks LS, Maxwell MH. Renal vein renin: value and limitations in the prediction of operative results. Urol Clin North Am 1975;2:311-25.

${ }^{48}$ Couch NP, Sullivan J, Crane C. The predictive accuracy of renal vein renin activity in the surgery of renovascular hypertension. Surgery 1976;79:70-6.

${ }^{4}$ Streeten DHP, Anderson GH, Freiberg JM, Dalakos TG. Use of an angiotensin II antagonist (saralasin) in the recognition of "angiotensinogenic" hypertension. $N$ EnglJ Med 1975;292:657-62.

${ }^{50}$ Russell GI, Bing RF, Thurston H, Swales JD. Plasma renin in hypertensive patients: significance in relation to clinical and other biochemical features. $Q J \operatorname{Med} 1980$; 149:385-94.

${ }^{51}$ Marks LS, Maxwell MH, Kaufman JJ. Renin, sodium and vasodepressor response to saralasin in renovascular and essential hypertension. Ann Intern Med 1977;87:176-82.

52 Thurston H, Swales JD. Influence of sodium restriction upon two models of renal hypertension. Clin Sci Mol Med 1976;51:275-9.

${ }^{53}$ Swales JD, Thurston H, Queiroz FP, Medina A. Sodium balance during the development of experimental hypertension. J Lab Clin Med 1972;80:539-47.

54 Thurston H, Bing RF, Swales JD. Reversal of two-kidney one clip renovascular hypertension in the rat. Hypertension 1980;2:256-65.

${ }^{55}$ Miller ED, Samuels AI, Haber E, Barger AG. Inhibition of angiotensin conversion and prevention of renal hypertension. Am J Physiol 1975;228:448-53.

${ }^{56}$ Thurston H, Swales JD. Comparison of angiotensin II antagonist and antiserum infusion with nephrectomy in the two kidney Goldblatt hypertensive rat. Circ Res 1974;35:325-9.

${ }^{57}$ Macdonald GJ, Boyd GW, Peart WS. Effect of the angiotensin II blocker 1-sar-8-ala-angiotensin II on renal artery clip hypertension in the rat. Circ Res 1975;37:6406. 
${ }^{58}$ Carretero OA, Gulati OP. Effects of angiotensin antagonist in rats with acute, subacute and chronic two-kidney renal hypertension. J Lab Clin Med 1978;91:264-71.

${ }^{9}$ Riegger AJG, Millar JA, Lever AF, Norton JJ, Slack B. Correction of renal hypertension in the rat by prolonged infusion of angiotensin inhibitors. Lancet 1977;ii:1317-9.

${ }^{60}$ Thurston H, Bing RF, Marks E, Swales JD. Response of chronic renovascular hypertension to surgical correction or prolonged blockade of the renin-angiotensin system by two inhibitors in the rat. Clin Sci Mol Med 1980;58: 15-20.

${ }^{61}$ Bengis RG, Coleman TG. Antihypertensive effect of prolonged blockade of angiotensin formation in benign and malignant one and two-kidney Goldblatt hypertensive rats. Clin Sci 1979;57:53-62.

62 Marks ES, Bing RF, Thurston H, Swales JD. Vasodepressor property of the converting enzyme inhibitor captopril (Sq 14225): the role of factors other than renin-angiotensin blockade in the rat. Clin Sci 1980;58:1-6.

${ }^{63}$ Russell GI, Bing RF, Thurston H, Swales JD. Surgical reversal of Goldblatt two-kidney one clip hypertension in rats during inhibition of the renin angiotensin system. Hypertension 1982;4: (in press).

61 Thurston H, Swales JD, Bing RF, Hurst BC. Marks ES. Vascular renin-like activity and blood pressure maintenance in the rat: Studies of the effect of changes in sodium balance, hypertension and nephrectomy.
Hypertension 1979;1:643-9.

${ }^{65}$ Brown JJ, Casals-Stenzel J, Cumming AMM, et al. Angiotensin II, aldosterone and arterial pressure: a quantitative approach. Hypertension 1979;1:159-79.

${ }^{66}$ Folkow B, Hallback M, Lundgren Y, Sivertsson R, Weiss L. Importance of adaptive changes in vascular design for establishment of primary hypertension studied in man and in spontaneously hypertensive rats. Circ Res 1973: 32, suppl $1: 2-16$.

67 Marks ES, Thurston H, Bing RF, Swales JD. Pressor responsiveness to angiotensin in renovascular and steroid hypertension. Clin Sci 1979;57:475-505.

${ }^{68}$ Gross F. The renin-angiotensin-system and hypertension. Ann Intern Med 1971;75:777-87.

${ }^{69}$ Floyer MA. The effect of nephrectomy and adrenalectomy upon the blood pressure in hypertensive and normotensive rats. Clin Sci $1951 ; 10: 405-21$.

${ }^{\circ}$ Muirhead EE. Antihypertensive functions of the kidney. (Arthur C Corcoran Memorial Lecture.) Hypertension $1980: 2: 444-64$

Requests for reprints to: Prof JD Swales, Department of Medicine, Clinical Sciences Building, PO Box 65. Leicester Royal Infirmary, Leicester, England. 